\title{
Influência da espermatogênese e dos níveis de testosterona no aspecto reprodutivo de codornas
}

\section{Lizandra Amoroso ${ }^{1}$, Silvana Martinez Baraldi Artoni ${ }^{1}$, Vera Maria Barbosa de Moraes ${ }^{2}$, Dilermano Perecin 3 , Vanessa Sobue Franzo 4 , Patrícia Amoroso ${ }^{5}$}

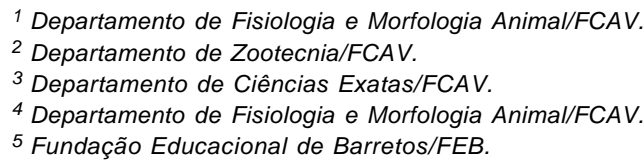

RESUMO - Analisaram-se os níveis de testosterona, o peso corporal, os pesos testiculares relativos e absolutos, a espessura da túnica albugínea, a altura do epitélio germinativo, o diâmetro e o número de figuras de meiose dos túbulos seminíferos dos testículos de 65 codornas machos no período de junho a outubro. As aves foram agrupadas em gaiolas (6 aves/gaiola) e alojadas em um galpão durante todo o período experimental. A análise morfométrica dos testículos foi realizada no período dos 60 aos 180 dias de idade. Os níveis de testosterona plasmática total foram dosados pelo método de radioimunoensaio com anticorpo marcado radiativamente. Conforme resultados da análise morfométrica, a concentração de testosterona circulante influenciou o comportamento do epitélio germinativo do testículo e teve atividade espermatogênica máxima durante o período de 110 a 130 dias de idade, evidenciando que a fase de maior atividade reprodutiva coincide com o início do fotoperíodo crescente, ou seja, no final de agosto ao início de setembro. O pico de testosterona foi anterior à espermatogênese máxima, evidenciando a preparação do sistema reprodutor para a fase proliferativa. Aos 180 dias de idade, ainda que submetidas aos dias longos no mês de outubro, as aves apresentaram baixos níveis de testosterona circulante e regressão de parâmetros testiculares.

Palavras-chave: Coturnix coturnix japonica, gametogênese, hormônio esteróide, morfometria, reprodução, testículo

\section{Spermatogenesis and testosterone levels influence on reproductive aspects of Japanese quails}

\begin{abstract}
Testosterone levels to the body weight, relative and absolute testes weights, tunica albuginea thickness, germinative epithelium height, diameter and meiosis picture numbers of seminiferous tubules of 65 male quails were evaluated from June to October. The birds were grouped in cages ( 6 birds/cage) and lodged in a shed during all experimental period. The testis morphometric analysis was carried out from 60 days to 180 days old. The total testosterone plasmatic levels were dosed by radioimmunoassay method with antibody radioactivity marked. The morphometric analysis result showed that testosterone concentrations influenced the bird testis germinal epithelium behavior, with maximum spermatogenic activity during the period of 110 to 130 days old, that demonstrate the phase of mayor reproductive activity coincided with the crescent photoperiod beginning, that is, in the end of August up to September beginning. The testosterone peak was prior to maximum spermatogenesis, to evidence the reproductive system preparation for proliferative phases. At 180 days old, still submitted to long days in October, the birds presented low circulate testosterone levels and testicular parameters regression.
\end{abstract}

Key Words: Coturnix coturnix japonica, gametogenesis, steroid hormone, morphometry, reproduction, testis

\section{Introdução}

Fatores como rápido desenvolvimento corporal, rusticidade e baixo consumo de ração favorecem a exploração comercial da codorna (Reis, 1979). Em virtude de sua importância zootécnica, é necessário o esclarecimento de algu- mas características reprodutivas da espécie, considerando as variações de testosterona e a influência de fatores estacionais, que podem estar associados ao crescimento e à regressão dos testículos em resposta à luz, temperatura, ao índice pluviométrico e à disponibilidade de alimento (Kemp, 1973). 
A organização anatômica e histológica do testículo da codorna é semelhante à do galo doméstico e do pombo (Baraldi-Artoni et al., 1997, 1999). Ainda que a forma dos testículos seja análoga, o testículo esquerdo é maior que o direito. O peso depende do estado funcional do órgão e representa $1 \%$ do peso vivo (PV) em galos (Hoffmann \& Volker, 1969) e 2,26\% do PV em codornas (Clulow \& Jones, 1982), nas quais a função testicular varia com a luminosidade. O peso do testículo é elevado em setembro, contrastando com o reduzido diâmetro dos túbulos seminíferos e com os poucos espermatozóides observados no período de luz em março. A atividade espermatogênica aumenta na primavera e no verão, estação reprodutiva da espécie (Baraldi-Artoni et al., 1999). Além de definir a estacionalidade da codorna, os dias longos estimulam a secreção de testosterona, que, por sua vez, modula o ritmo circadiano (Lumineau et al., 1998) e oscila de acordo com a variação volumétrica testicular e as peculiaridades da estação reprodutiva de cada espécie (Bacon et al., 1994).

A espermatogênese é regular e bem definida em aves. (Lin et al., 1990; Baraldi-Artoni et al., 1997; Madekurozwa et al., 2002). A codorna apresenta ciclo anual dividido em quatro fases, denominadas repouso, recrudescência, proliferação e regressão. As fases sucedem-se ao longo do ano e apresentam o comprimento do fotoperíodo como principal influência exógena sobre sua frequiência e duração (BaraldiArtoni et al., 1997).

É importante esclarecer peculiaridades da codorna, entre elas, o desenvolvimento testicular e os níveis plasmáticos de testosterona, a fim de promover a seleção e o controle genético de exemplares com produção espermática apreciável. Este trabalho foi realizado com o objetivo de investigar o comportamento da espermatogênese e da testosterona durante o período reprodutivo do macho.

\section{Material e Métodos}

Foram utilizadas 115 codornas de 1 dia de idade, provenientes da Universidade Estadual de Maringá, PR, alojadas em galpão do Setor de Avicultura do Departamento de Zootecnia da Faculdade de Ciências Agrárias e Veterinárias (FCAV), da Unesp, em Jaboticabal, SP. Durante a fase de cria, as codornas foram mantidas agrupadas em um círculo com lâmpada infravermelho, bebedouro infantil para frango de corte e comedouro tipo prato. Quando atingiram 25 dias de idade, as aves foram submetidas à sexagem. Selecionaram-se 65 machos para a fase experimental, dos quais foram colhidos 50 testículos para a análise histológica e 65 amostras sanguíneas para a dosagem hormonal. Os machos foram disribuídos em gaiola de arame galvanizado (6 aves/ gaiola) com comedouro tipo calha e bebedouro tipo nipple, onde foram mantidos durante a recria e a fase adulta. A fim de estimular a libido, os machos foram dispostos de maneira intercalada para que tivessem contato visual com as fêmeas da mesma idade. As codornas tiveram água à vontade, foram alimentadas com ração balanceada, proveniente da Fábrica de ração da FCAV (Tabela 1), e foram mantidas sob regime de 17 horas diárias de luz. No período dos 60 aos 180 dias de idade, cinco aves foram levadas a cada dez dias ao Laboratório de Anatomia do Departamento de Morfologia e Fisiologia Animal. Depois de 20 minutos de descanso, as codornas foram anestesiadas com éter etílico, sacrificadas mediante deslocamento das vértebras cervicais e pesadas com o auxílio de balança de precisão. Após abertura da cavidade abdominal e evisceração do trato gastrintestinal, os testículos foram localizados e extraídos com pinças e tesouras cirúrgicas. Posteriormente, os órgãos foram pesados para determinação dos pesos absoluto e relativo dos testículos, de modo que o primeiro correspondeu ao peso corporal da ave e o segundo ao peso do testículo em relação ao peso corporal. O órgão direito foi seccionado e seus cortes foram destinados à rotina histológica. Cada lâmina (uma para cada animal) continha três cortes histológicos de $7 \mu \mathrm{m}$ de espessura, corados segundo técnica de hematoxilina e eosina (HE).

Para a avaliação morfométrica do testículo das aves, utilizou-se um microscópio binocular Olympus BX 50, equipado com câmera digital. Foram fotografados aleatoriamente 30 campos com área de $588.785,4 \mathrm{~mm}^{2}$, em aumento de 200X. As imagens fotografadas foram analisadas em um computador utilizando-se o software Image Pro Plus, Media Cybernetics, Brasil, para avaliar a espessura da túnica albugínea, o diâmetro dos túbulos seminíferos, a altura do epitélio germinativo e o número de figuras de meiose dos túbulos seminíferos.

Aos 60 dias de idade, procedeu-se à coleta de sangue de cinco aves, a cada dez dias, até que completassem 150 dias de idade. Amostras de $1 \mathrm{~mL}$ foram coletadas diretamente do coração por meio de seringas de insulina descartáveis heparinizadas, colocadas em tubos ependorf e acondicionadas em caixas de isopor com gelo até o processamento. As amostras foram centrifugadas a $3.000 \mathrm{rpm}$ por 15 minutos a $4^{\circ} \mathrm{C}$ e o plasma foi separado e congelado a $-20^{\circ} \mathrm{C}$ até a aplicação da técnica de radioimunoensaio. Para as dosagens de testosterona, realizadas utilizando-se okit Testosterona Total Coat - A - Count ${ }^{\circledR}$, foram necessários $50 \mu \mathrm{Lde}$ plasma de cada amostra.

Durante o desenvolvimento do método, foram utilizados tubos de polipropileno $12 \times 75 \mathrm{~mm}$ devidamente identificados. Em cada tubo de plástico foram depositados $50 \mu \mathrm{L}$ 
Tabela 1 - Composição da ração experimental (\%MS)

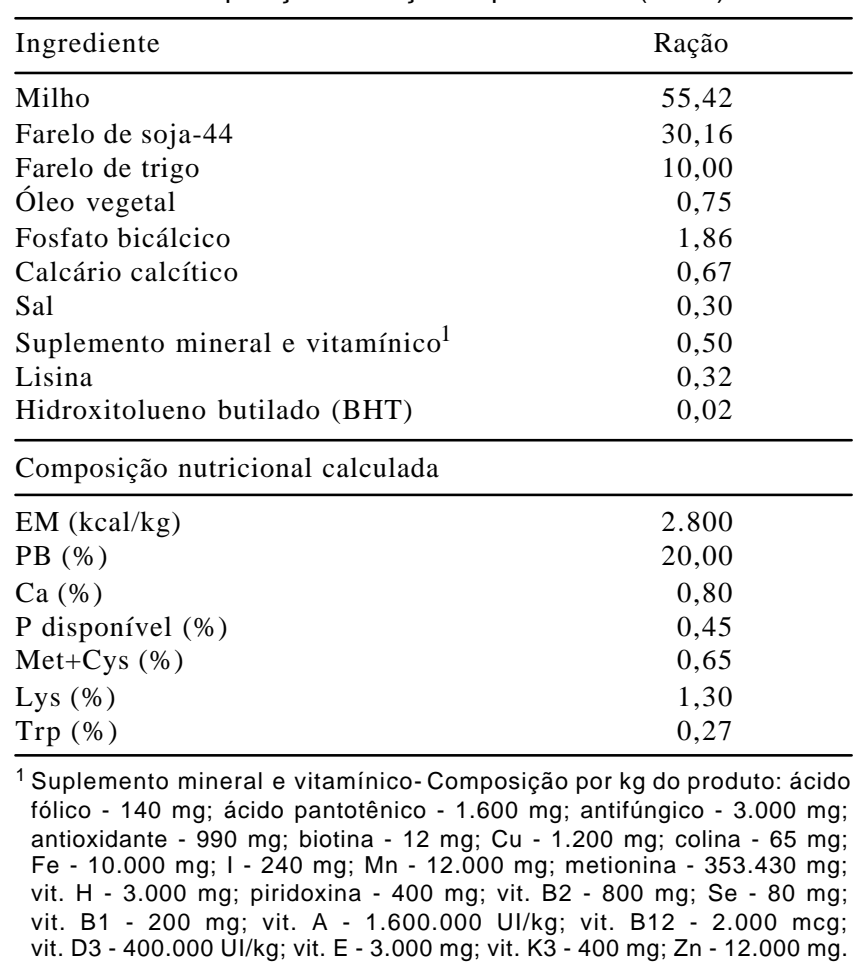

de plasma e, em seguida, foi adicionado $1,0 \mathrm{~mL}$ da solução contendo $\mathrm{I}^{125}$. Os tubos foram agitados e mantidos em banho-maria durante 3 horas a $37^{\circ} \mathrm{C}$. Com a decantação, o material precipitado ficou aderido à superfície dos tubos, que foram invertidos sob papel absorvente para remoção do líquido remanescente. Posteriormente, realizou-se a contagem da radioatividade por meio de um contador gama. Os dados foram analisados estatisticamente por meio de análise de variância (SAS, 2002) e as médias foram comparadas pelo teste Tukey, considerando o nível de $5 \%$ de significância.

\section{Resultados e Discussão}

O peso corporal e os pesos absolutos e relativos dos testículos não diferiram $(\mathrm{P}>0,05)$ no período de 70 a 180 dias (Tabela 2). Considerando o período de 110 a 130 dias, quando a atividade espermatogênica foi elevada, não houve aumento $(\mathrm{P}>0,05)$ do peso testicular, apesar de os ciclos espermatogênicos das aves estarem associados à variação de peso do órgão (Hoffmann \& Volker, 1969). Bluhm et al. (2000) observaram o peso corporal e o tamanho das gônadas de patos selvagens (Anas platyrhynchos) mantidos sob luz natural durante o inverno canadense (final de outubro até o início de março) e estudaram o efeito da formação de casais sobre o desenvolvimento testicular e neuroendócrino destas aves. Esses autores observaram
Tabela 2 - Peso corporal e pesos testiculares, absoluto e relativo de codornas japonesas no período dos 70 aos 180 dias de idade

\begin{tabular}{lccc}
\hline $\begin{array}{l}\text { Idade da } \\
\text { ave }(\text { dias })\end{array}$ & $\begin{array}{c}\text { Peso corporal } \\
(\mathrm{g})\end{array}$ & $\begin{array}{c}\text { Peso absoluto } \\
(\mathrm{g})\end{array}$ & $\begin{array}{c}\text { Peso relativo } \\
(\%)\end{array}$ \\
\hline 70 & $128,89 \pm 10,14$ & $2,80 \pm 0,16$ & $2,18 \pm 0,2$ \\
80 & $130,68 \pm 8,85$ & $2,95 \pm 1,27$ & $2,53 \pm 1,0$ \\
90 & $133,44 \pm 10,53$ & $2,95 \pm 0,68$ & $2,24 \pm 0,3$ \\
100 & $140,13 \pm 4,82$ & $2,73 \pm 0,57$ & $1,94 \pm 0,4$ \\
110 & $149,84 \pm 4,07$ & $3,51 \pm 0,67$ & $2,35 \pm 0,5$ \\
120 & $154,71 \pm 13,06$ & $3,28 \pm 0,48$ & $2,11 \pm 0,2$ \\
130 & $152,71 \pm 8,61$ & $3,15 \pm 0,51$ & $2,19 \pm 0,4$ \\
140 & $153,09 \pm 15,15$ & $2,93 \pm 0,26$ & $1,96 \pm 0,3$ \\
150 & $144,42 \pm 17,56$ & $2,69 \pm 0,66$ & $1,88 \pm 0,5$ \\
160 & $143,07 \pm 8,97$ & $3,40 \pm 0,75$ & $2,36 \pm 0,2$ \\
170 & $150,11 \pm 16,70$ & $2,74 \pm 0,19$ & $2,06 \pm 0,7$ \\
180 & $152,52 \pm 15,31$ & $2,93 \pm 0,98$ & $2,08 \pm 0,4$ \\
\hline
\end{tabular}

aumento significativo da massa gonadal durante o período de 28 de janeiro a 3 de março, o que evidencia resposta positiva ao fotoperíodo.

Apesar de ser outra espécie aviária, a codorna japonesa pode ser comparada ao pato selvagem por ser uma ave semidoméstica e sazonal. Assim, ao contrário do observado por Bluhm et al. (2000), nesta pesquisa verificou-se relativa estabilidade do peso testicular no período de junho a outubro, ou seja, no final do outono até o início da primavera (Tabela 2). Esses resultados podem estar relacionados à alimentação balanceada do lote homogêneo das aves utilizadas neste ensaio, considerando peso, idade, manejo e sexo.

Os parâmetros testiculares das aves diferiram significativamente durante o período de 60 a 180 dias de idade (Figuras 1, 2, 3, 4, 5, 6, 7, 8). Nos períodos de 60 a 80 dias e de 150 a 180 dias, os diâmetros dos túbulos seminíferos foram semelhantes; elevaram-se aos 90 e 110 dias, apresentaram pico aos 120 e 130 dias de idade $(\mathrm{P}<0,05)$ e reduziram até os 150 dias permanecendo inalterados até os 180 dias $(\mathrm{P}>0,05)$. Assim, constatou-se que a espermatogênese se manteve homogênea no início e no final do período experimental e apresentou-se elevada dos 110 aos 130 dias. (Figuras 2 e 1B).

O diâmetro dos túbulos seminíferos das aves mantiveram-se estáveis dos 60 aos 80 dias de idade, resultados que estão de acordo com os descritos por Baraldi-Artoni et al. (1997, 1999), que encontraram notável redução dos túbulos seminíferos em codornas durante o mês de março, período em que as aves estavam sob fotoperíodo decrescente. No entanto, aos 120 e aos 130 dias de idade, tanto o diâmetro dos túbulos seminíferos como a altura do epitélio germinativo apresentaram valores elevados em relação aos demais dias, indicando (Figura 2) expressiva atividade 

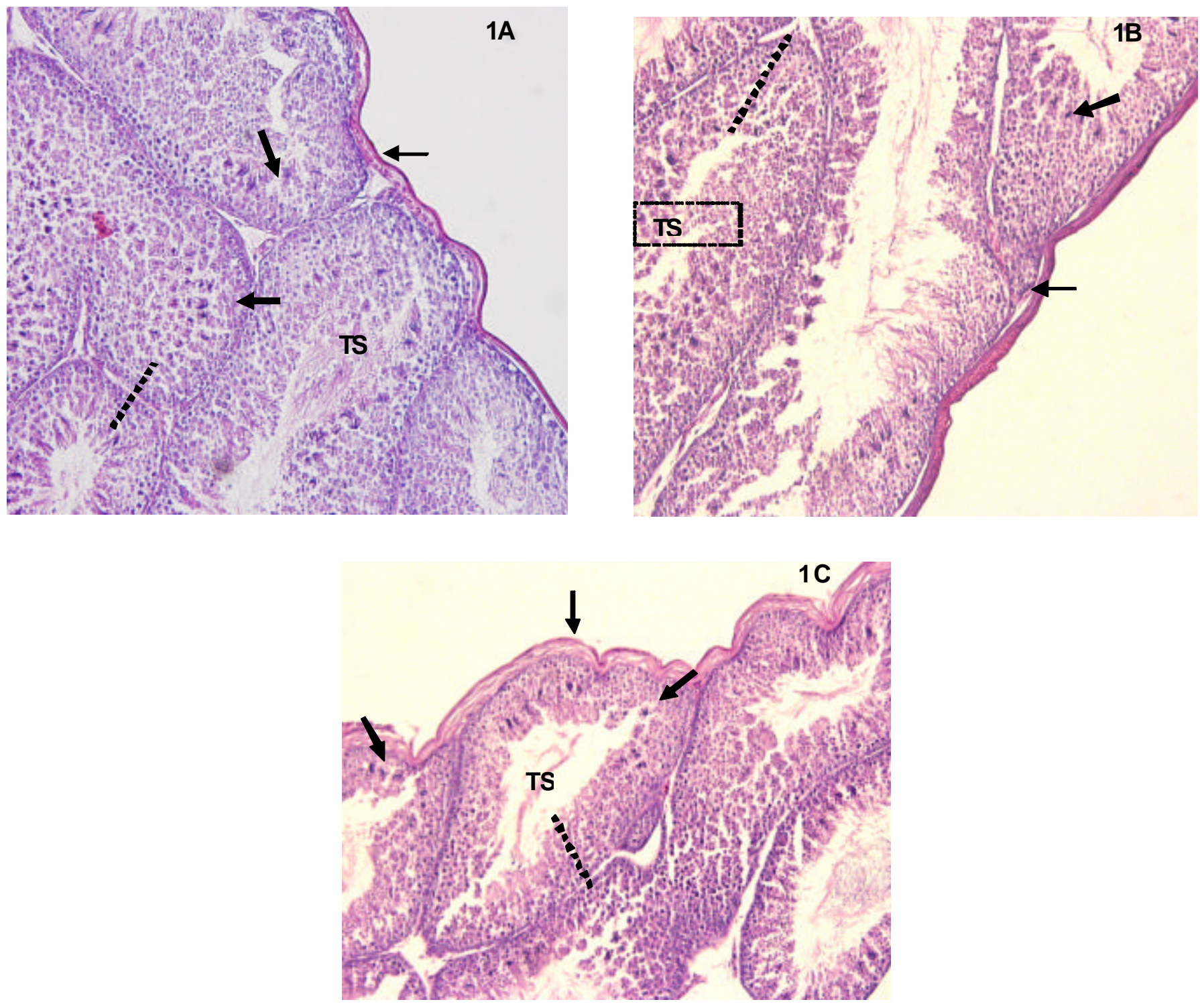

Figura 1 - Fotomicrografias de testículo de codornas japonesas aos 80 (FIG1A), aos 130 (FIG1B) e aos 180 (FIG1C) dias de idade. Observam-se a túnica albugínea (seta fina), o túbulo seminífero (TS), a altura do epitélio germinativo (pontilhado), o número de figuras de meiose (seta grossa) e a coloração. Hematoxilina - eosina, 200X.
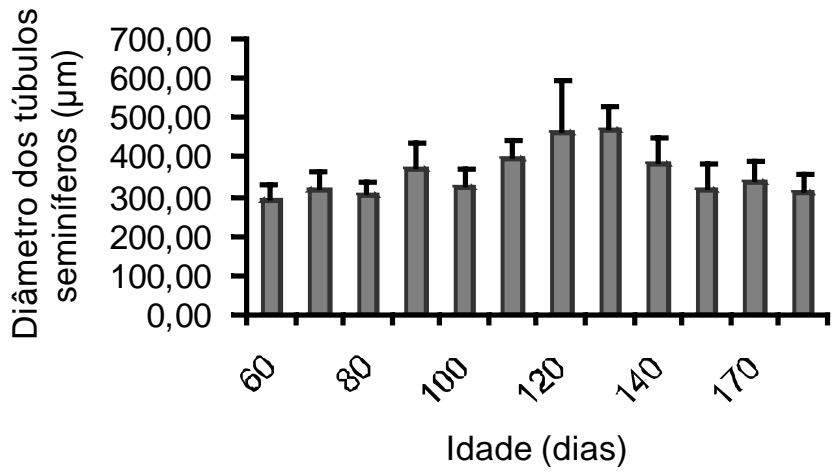

Figura 2 - Diâmetro dos túbulos seminíferos de testículos de codornas japonesas no período dos 60 aos 180 dias de idade. espermatogênica associada aos períodos de dias longos, semelhante ao exposto por Baraldi-Artoni et al. (1999), que observaram fase de maior atividade durante a primavera.

Os valores de altura do epitélio germinativo obtidos aos 60 dias e no período dos 150 aos 180 dias $(\mathrm{P}>0,05)$ foram semelhantes e sugerem que nesses dias a altura do epitélio se manteve constante, elevando-se dos 70 até os 110 dias, com uma fase ativa de espermatogênese com pico máximo dos 120 aos 140 dias.Subseqüentemente, a altura do epitélio germinativo regrediu $(\mathrm{P}<0,05)$ aos 150 dias e apresentou tendência linear até 180 dias (Figuras 3 e 1C).

O número de figuras de meiose manteve-se estável dos 60 aos 80 dias, em resposta à manutenção no número das células espermatogênicas neste período; aumentou até os 


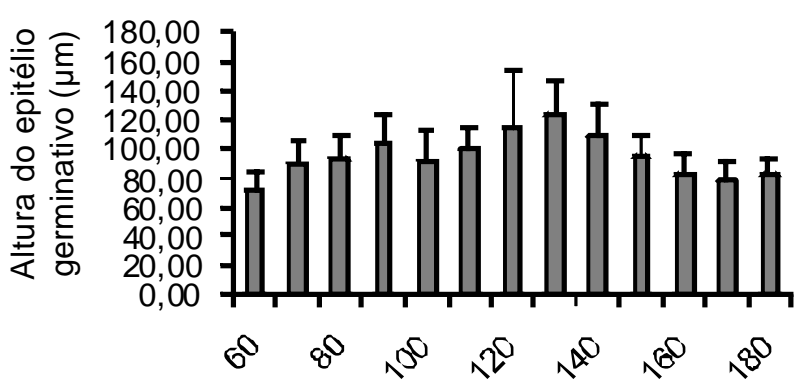

Figura 3 - Altura do epitélio germinativo de testículos de codornas japonesas no período dos 60 aos 180 dias de idade.

90 dias $(\mathrm{P}<0,05)$ e depois regrediu até os 120 dias, aumentando $(\mathrm{P}>0,05)$ novamente dos 120 aos 180 dias, o que caracteriza importante atividade espermatogênica, com pico máximo aos 90 dias.Durante o período dos 60 aos 80 dias e dos 120 aos 180 dias, verificou-se tendência linear de aumento no número de figuras de meiose (Figura 1). O número de figuras de meiose tendeu a apresentar estabilidade dos 60 aos 80 dias, inferior $(\mathrm{P}<0,05)$ aos demais dias, porém suficiente para evidenciar a atividade espermatogênica da codorna. Além disso, o número de figuras de meiose dos 100 aos 180 dias manteve-se em um patamar que pode ser mantido pelo fotoperíodo (Figura 4).

A concentração de testosterona dos 60 aos 150 dias de idade (Figura 5) não variou ( $>>0,05)$. Apesar de extremamente baixa aos 60 dias, a concentração plasmática de testosterona aumentou dos 70 aos 90 dias, quando apresentou o pico máximo, e regrediu gradativamente aos 150 dias, embora em nível bem mais elevado que o observado aos 60 dias (Figura 5).

Em aves tropicais como a codorna japonesa, a atividade reprodutiva ocorre de forma sincronizada com o fotoperíodo e fatores endógenos, que fazem parte desses ajustamentos, favorecendo uma seqüência de atividades testiculares. Assim, as aves apresentam processos fisiológicos que induzem à fotossensibilidade, que ocorre no início dos dias longos, levando ao desenvolvimento gonadal (Nicholls et al., 1988).

Como regra geral, fotoperíodos decrescentes retardam a maturidade sexual, enquanto fotoperíodos longos estimulam a atividade sexual (Sturkie, 1968). A túnica albugínea apresentou-se espessa dos 60 aos 70 dias de idade e máxima aos 180 dias (Figura 1C), destacando neste período o início e o final da atividade reprodutiva da codorna, respectivamente, dados que corroboram as investigações de Fuenzalida et al. (1989), que observaram espessamento da túnica albugínea no início e no final da atividade reprodutiva. Contudo, durante o período de atividade espermatogênica,

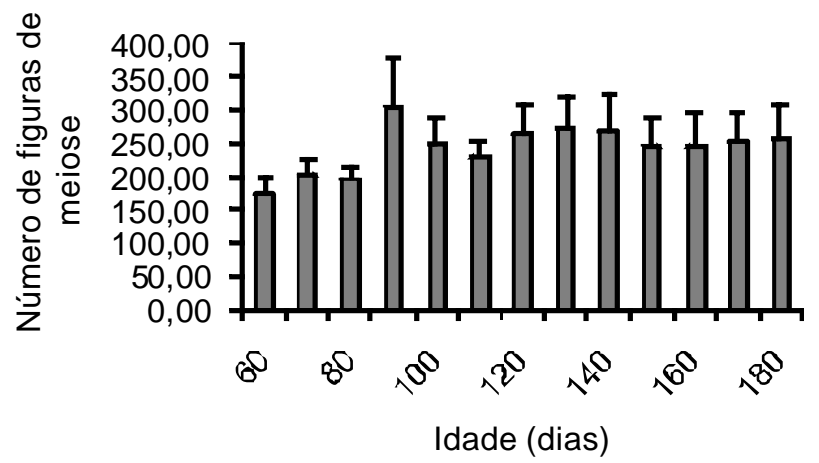

Figura 4 - Número de figuras de meiose de testículos de codornas japonesas no período de 60 a 180 dias de idade.

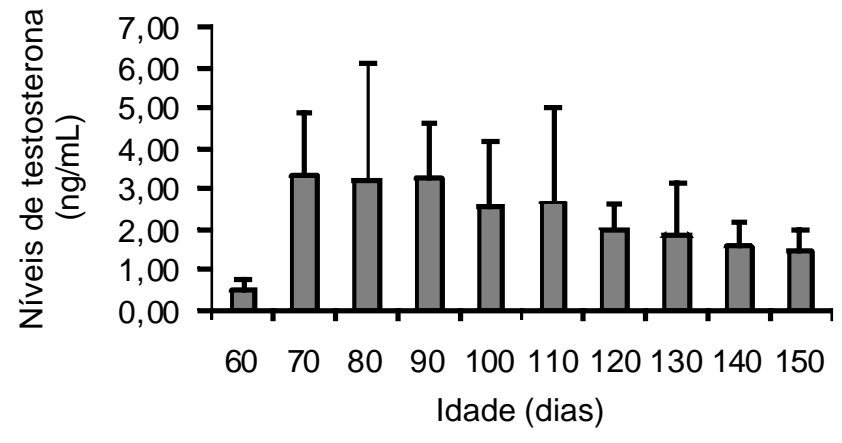

Figura 5 - Níveis de testosterona em codornas japonesas no período de 60 a 180 dias de idade.

observada por meio do diâmetro dos túbulos seminíferos e da altura do epitélio germinativo, a túnica albugínea mostrou-se extremamente fina $(\mathrm{P}<0,05)$.

Burke (1988) observou que, no início do período fotoestimulador, ocorre aumento nos níveis sangüíneos de hormônio luteinizante ( $\mathrm{LH})$ e do folículo-estimulante (FSH). Os níveis desses hormônios reduzem à medida que a influência por feedback negativo da testosterona é exercida. Neste experimento, os níveis de testosterona não variaram ( $\mathrm{P}>0,05)$ no período de 60 a 150 dias de idade, apesar de, em valores absolutos, os valores terem sido extremamente baixos aos 60 dias de idade, período de recrudescência da codorna, sugerindo que nesta idade as aves apresentavam altos níveis de $\mathrm{LH}$ e FSH, exercendo feedback negativo sobre a testosterona. Dos 70 aos 90 dias, provavelmente houve retroalimentação negativa da testosterona sobre a secreção de LH, o que correspondeu ao período pré-reprodutivo. Os níveis de testosterona reduziram e se mantiveram relativamente homogêneos até os 150 dias indicando estabilidade na produção hormonal durante a fase reprodutiva.

Hau et al. (2000) estudaram os níveis de testosterona plasmática, o comportamento e o ciclo reprodutivo da 
espécie Hylophylax naevioide e observaram que os níveis da testosterona aumentaram no início da primavera e permaneceram elevados durante o período reprodutivo, situações não observadas na codorna doméstica.

\section{Conclusões}

A concentração de testosterona varia sazonalmente; apresenta picos no início da fase reprodutiva e redução progressiva durante a fase de regressão testicular, ou seja, no final da primavera. Além disso, este esteróide influencia no comportamento do epitélio germinativo do testículo, mas não causa variação evidente no peso testicular, mantendo atividade espermatogênica máxima durante o período de 110 a 130 dias de idade. A espessura da túnica albugínea, o diâmetro dos túbulos seminíferos, a altura do epitélio germinativo e o número de figuras de meiose dos túbulos seminíferos apresentaram os maiores valores médios durante a fase reprodutiva, principalmente de agosto a setembro. Verificou-se tendência de aumento generalizado desses parâmetros em idêntica fase do ciclo em várias espécies de aves estudadas.

\section{Agradecimento}

Ao Prof. Dr. José Wanderley Cattelan, pela cordial colaboração, pela disponibilidade constante e pelo incentivo durante a execução do trabalho, e ao técnico de laboratório Orandi Mateus, pelo auxílio na confecção das lâminas histológicas.

\section{Literatura Citada}

BACON, W.L.; LONG, D.W.; KURIMA, K. et al. Coordinate pattern of secretion of luteinizing hormone and testosterone in mature male turkeys under continuous and intermittent photoschedules. Poultry Science, v.73, n.6, p.864-870, 1994.
BARALDI-ARTONI, S.M.; ORSI, A.M.; CARVALHO, T.L.L. et al. The annual testicular cycle of the domestic quail (Coturnix coturnix japonica). Anatomia, Histologia y Embryologia, v.26, n.4, p.337-339, 1997.

BARALDI-ARTONI, S.M.; ORSI, A.M.; CARVALHO, T.L.L. et al. Seasonal morphology of the domestic quail (Coturnix coturnix japonica) testis. Anatomy Histology Embryology, v.28, n.4, p.217-220, 1999.

BLUHM, C.K.; ROZENBOIM, I.; SILSBY, J. et al. Sex-related differences in the effects of late winter pairing activity and seasonal influences on neuroendocrinology and gonadal development of mallards. General and Comparative Endocrinology, v.118, n.1, p.310-321, 2000.

BURKE, W.H. Reprodução das aves. In: SWENSON, M.J. (Ed.) Dukes: fisiologia dos animais domésticos. 10.ed. Rio de Janeiro: Guanabara Koogan, 1988. p.731-743.

CLULOW, J.; JONES, R.C. Production, maturation, storage and survival of spermatozoa in the male Japanese quail, Coturnix coturnix. Journal of Reproductive and Fertility, v.64, n.2, p.259-266, 1982.

FUENZALIDA, H. Morfologia del testiculo de Pygoscelis papua (FOSTER) durante el período de actividad sexual. Archivos de Anatomía y Embriología, v.20, p.79-91, 1989.

HAU, M. Timing of breeding in variable environments: tropical birds as model systems. Hormone Behavior, v.40, n.2, p.281-290, 2001.

HOFFMANN, G.; VÖLKER, H. Anatomía y fisiología de las aves domesticas. 1.ed. Zaragoza: Acribia, 1969. 190p.

KEMP, A.C. Environmental factors affecting the onset breeding in some Southern African hornbills, Tockus spp. Journal of Reproduction and Fertility, v.19, p.319-31, 1973.

LIN, M.; JONES, M.L.R.C.; BLACKSHAW, A.W. The cycle of the seminiferous epithelium in the japanese quail (Coturnix coturnix japonica) and estimation of its duration. Journal of Reproduction and Fertility, v.88, n.2, p.481-490, 1990.

LUMINEAU, S.; GUYOMARC'H, C.; BOSWELL, T.D. et al. Induction of circadian rhythm of feeding activity by testosterone implantations in arrhythmic Japanese quails males. Journal of Biological Rhythms, v.13, n.1, p.278-287, 1998.

MADEKUROZWA, M.C.; CHABVEPI, T.T.; MATEMA, S. et al. Relationship between seasonal changes in spermatogenesis in the juvenile ostrich (Stuchio camelus) and the presence of the LH receptor and 3 b-hydroxysteroid dehydrogenase. Reproduction, v.123, n.5, p.735-42, 2002.

NICHOLLS, T.J.; GOLDSMITH, A.R.; DAWSON, A. Photofractoriness in birds and comparison with mammals. Phisiological Reviews, v.68, n.1, p.133-176, 1988.

REIS, L.F.S.D. Codornizes: criação e exploração. 1.ed. Lisboa: Arte Final, 1979. 222p.

STATISTICAL ANALYSIS SYSTEMS - SAS. User's guide: statistics, version 9.00 4.ed. Cary: 2002. (CD-ROM).

STURKIE, P.D.Fisiología aviar. 2.ed. Zaragoza: Acribia, 1968. $467 \mathrm{p}$. 